\title{
Notas
}

\section{Do conceito estratégico de segurança alimentar ao plano de ação da FAO para combater a fome.}

\author{
ÁLVARO GURGEL DE ALENCAR
}

No society can surely be flourishing and happy, of which the greater part of the members are poor and miserable.

Adam Smith, 1776

Quero convidá-los a visualizar, num futuro não muito distante, ... uma nação em que os menos afortunados e os menos aptos não sejam condenados a permanecer à margem do corpo social, mas dele recebam apoio solidário com vistas a sua integração na coletividade;... Tancredo Neves, 17 de março de 1985

No ano de 1996, a Organização para Alimentação e Agricultura (FAO) realizou a Cúpula Mundial da Alimentação, conferência na qual foram aprovados uma Declaração e um Plano de Ação destinados a combater a fome no mundo. Os chefes de Estado e governo participantes assumiram então o compromisso de mudar radicalmente o quadro de desnutrição que afetava (e ainda afeta) mais de 800 milhões de homens, mulheres e crianças no mundo inteiro, dos quais um número substancial no Brasil. Neste ano, 2001, aquela Organização está novamente convidando chefes de Estado e de governo para reverem o progresso alcançado no atingimento das metas adotadas em 1996.

A perspectiva dessa reunião de cúpula, a ter lugar em Roma no próximo mês de novembro, faz renascer cinco anos depois a esperança de atrair a atenção da opinião pública, das instituições financeiras internacionais e das organizações não-governamentais para a persistência do dramático problema da fome. Levanos também a revisitar o conceito de segurança alimentar e considerar sua importância estratégica no mundo de hoje, nos planos nacional e internacional.

A segurança alimentar foi o fator crítico na evolução inicial da espécie humana e no posterior desenvolvimento das civilizações. Para um clã, uma tribo ou um povo primitivo, obter alimento em quantidade suficiente equivalia a assegurar a 
sobrevivência coletiva. Nos tempos primordiais, tomados os agrupamentos humanos em seu conjunto, o nível de segurança alimentar delimitou estreitamente a margem de sobrevivência da própria espécie, pela via altamente seletiva do progresso de uns e da eliminação pura e simples de outros.

A partir do período neolítico, nenhuma outra mudança terá tido tanta influência nas gerações subseqüentes quanto a que o antepassado do homem experimentou ao se transformar em pastor e agricultor, deixando assim de depender exclusivamente da caça e do extrativismo para nutrir-se. Os desenvolvimentos nos períodos seguintes da pré-história, bem como a ordem em que ocorreram nas várias coletividades humanas, não são conhecidos em todos os seus detalhes. Parece certo, contudo, que as exigências do incipiente processo de produção e a possibilidade de preservar e armazenar alimentos, em vez de ter que consumi-los imediatamente, tiveram forte impacto na organização daquelas comunidades. Pela primeira vez, seus integrantes começaram a acumular recursos excedentes (estoques de alimentos, sementes e animais) e tiveram necessidade de proteger essa nova riqueza dos predadores e das intempéries. Foram levados assim a desenvolver atividades e misteres antes inexistentes.

A um ritmo cada vez mais rápido em comparação com as fases anteriores, o ser humano foi ampliando sua inteligência aplicada e seu acervo de conhecimentos. Desenvolviam-se técnicas agrícolas, observavam-se as condições meteorológicas, selecionavam-se as melhores sementes, apareciam os implementos agrícolas e também as primeiras construções inteiramente artificiais - paióis, currais, cisternas, canais, moradias e fortificações. Reforçada sua segurança alimentar, o homem se tornava também menos vulnerável, porque melhor alimentado e protegido, e multiplicava-se a uma taxa acelerada, integrando-se em comunidades mais numerosas e espalhando-se por várias regiões do globo. Esses povos buscaram, via de regra, as terras que mais se prestavam ao cultivo e às pastagens freqüentemente os vales férteis, capazes de suportar com segurança grandes populações. Não terá sido mera coincidência que, antes da expansão dos transportes e do comércio e do florescimento dos povos mediterrâneos, quase todas as civilizações que deixaram registro tenham proliferado nas bacias de rios como o Huang Ho, o Indus, o Tigre e o Eufrates, o Nilo e o Jordão.

Mesmo em estágios bem mais avançados da evolução histórica das sociedades, a segurança alimentar continuou sendo um elemento crítico e uma constante preocupação das elites, que desejavam preservar seu modelo políticosocial e perpetuar-se no poder. A pax romana dependia da satisfação dos súditos, assegurada através da fórmula pane et circensis (nesta ordem). Roma se alimentava principalmente dos grãos cultivados pelas colônias, nos campos da Europa transalpina e da planície costeira, então verdejante, do norte da África. Cartago foi destruída por ameaçar a segurança alimentar de Roma. As invasões 
de povos bárbaros em demanda dessas terras férteis na periferia do império romano marcaram o início de seu declínio.

Toda vez que, no curso da história, a segurança alimentar foi gravemente afetada, a incapacidade de restabelecê-la foi seguida, mais cedo ou mais tarde, de sérios distúrbios sociais: comoções internas determinando mudanças no poder, amplos movimentos migratórios em busca de regiões mais férteis ou, até mesmo, o fim de um Estado, quer vítima de conquista ou de rápido declínio e eventual colapso. No Egito bíblico, a epidemia de fome que consumiria o reino do Faraó somente foi evitada pela estratégia de armazenamento e distribuição de grãos idealizada e posta em prática por José; do outro lado do mundo, os maias, mais de mil anos depois, não tiveram a mesma sorte ou engenhosidade, e simplesmente implodiram como civilização. Várias dinastias chinesas foram, em certos momentos, abaladas por reações à fome, entre as quais, no século dezenove, a rebelião Tai-ping - que durou mais de uma década - e, em 1910-11, a série de rebeliões detonadas pela fome em massa, causadoras da queda da dinastia Manchu e da instalação da república. A história da Europa, por sua vez, está repleta de revoltas, conflitos, migrações e invasões causadas, em última análise, pela fome endêmica, epidêmica ou cíclica (sazonal).

Quando o desequilíbrio agudo entre a demanda e a oferta de alimentos não era corrigido por um desses meios, a natureza dava sua inexorável contribuição. A inanição, bem como as doenças e pestes propagadas pela desnutrição e pela falta de higiene, rapidamente reduziam a demanda, ceifando o número de vidas necessário para restabelecer um certo equilíbrio.

Embora esse angustiante problema houvesse, ao longo dos tempos, preocupado não poucos pensadores, foi Thomas Robert Malthus, pastor anglicano e professor quem, em 1798, primeiro o abordou com alguma contundência, valendo-se de um raciocínio que hoje chamaríamos macro-econométrico. Malthus sustentava que o que ele denominava força da população era muito maior que a força da terra para prover a subsistência do homem, já que a primeira, se não controlada, se expandia em razão geométrica, enquanto a segunda crescia em razão aritmética. Aceitando como incontrolável a paixão entre os sexos, Malthus considerou definitiva a tese de que só a miséria das massas e seu parcial extermínio podiam conduzir à necessária equalização daquelas duas forças desiguais.

Vê-se por seus escritos, entretanto, que o universo teórico com que lidava o piedoso pastor era a humanidade como um todo. Nesses termos, sua tese, mesmo se contasse com pressupostos mais sólidos do que os utilizados por ele, não podia prever a possibilidade - que hoje é uma realidade - de fazer crescer a produção global de alimentos a taxas mais altas que a do crescimento da população mundial. O triste paradoxo é que, se Malthus foi amplamente ultrapassado no atacado, sua observação empírica até hoje se repete no varejo. De fato, para o mundo como um todo, a produção de alimentos per capita aumentou 5\% na década de 1980, mas 
75 países em desenvolvimento - cerca da metade deles - produzia menos alimentos per capita ao final daquela década do que no seu início. Essa situação não experimentou melhora significativa na década de 90. Abstração feita da dinâmica do crescimento populacional e seu controle, os constantes avanços científicos na agricultura e mais recentemente a revolução verde, que invalidaram a proposição malthusiana em termos globais, têm sido mais que neutralizados, em casos específicos, pelas rígidas limitações (de ordem econômica, política e social) à produção de alimentos e à sua distribuição universal em função da necessidade.

Uma análise retrospectiva da importância estratégica da segurança alimentar se afigura relevante como pano de fundo para o exame do problema nos dias que correm. Primeiro, para se recordar a estreita correlação que sempre existiu entre a incidência da fome e a ocorrência de convulsões sociais, vale dizer, entre a higidez das populações e a saúde política das tribos, nações ou estados, i.e. sua estabilidade. Mesmo nos tempos modernos, muitos países têm pagado um preço alto por não resolverem o problema da fome. Em segundo lugar, tal retrospecto nos permite reter a noção de que a persistência da fome e da miséria pode redundar não só em ameaça à estabilidade interna, mas também em pressões ou interferência de origem externa. Tal como ao longo da história, hoje em dia grandes contingentes populacionais de países com déficit alimentar procuram escapar à miséria, qualquer que seja sua causa, emigrando para outros países. Na medida em que a maioria dos países de destino atualmente mais procurados - os afluentes - fecham gradualmente suas fronteiras à imigração, essas correntes migratórias internacionais tenderão a reorientar-se para países emergentes dotados de amplos espaços e legislações de imigração mais flexíveis, resultando em pressões políticas, disputas e inquietação social indesejadas para estes últimos.

Além disso, teses mais recentes, como good governance e teorias do tipo direito de ingerência, tendem a ser invocadas com mais freqüência em situações as mais diversas, e com propósitos muitas vezes espúrios, na medida em que a atitude (ou a inação) de algum país possa ser caracterizada como recusa ou incapacidade de observar adequadamente certos valores tidos como universais, como por exemplo os direitos humanos, entre os quais se arrola o direito à alimentação. Configura-se atualmente, para países ricos, médios ou pobres, o imperativo de atribuir à segurança alimentar - quer em termos globais quer nacionais - importância estratégica decisiva para a preservação de seus interesses, cada vez mais próximos do interesse da manutenção da paz e segurança internacionais. Tentar fazer com que esses interesses comuns sejam clara e amplamente percebidos é missão que deve incumbir a todos aqueles que se ocupam do assunto, seja em nível teórico, decisório ou operacional, já que somente assim se produzirá a necessária mobilização das vontades para enfrentar o problema.

Atualmente, o grau de segurança (vale dizer, de insegurança) alimentar no mundo, inclusive no Brasil, é regularmente capturado em índices da FAO. São sete 
indicadores globais, utilizados desde meados da década de 70: relações entre estoques e demanda globais, entre estoques finais e vendas, modificações na produção de três grupos de países e movimentos de preço internacionais, todos esses indicadores referindo-se a cereais. Utiliza-se também um índice domiciliar agregado por país e um monitoramento de tendências e fatores de vulnerabilidade em nível nacional, bem como uma série de outros dados e medições auxiliares cada vez mais sofisticados. O nível global de segurança alimentar assim medido tem-se deteriorado nos últimos vinte anos, embora tenha apresentado alguma melhora na segunda metade da década que se encerrou. Há perspectivas de melhora em vários países situados muito baixo na escala (países de baixa renda com déficit alimentar), porém o índice domiciliar agregado está há tempos abaixo da tendência em cerca de metade dos países analisados.

Os movimentos desses indicadores técnicos, muitas vezes incrementados numa direção ou noutra, são úteis para o acompanhamento da situação e para a definição de políticas setoriais. Mas os dados que chocam e apresentam maior relevância para estimular a implantação de políticas globais e nacionais são a existência - estimada pela FAO - de aproximadamente 826 milhões de pessoas cronicamente desnutridas no mundo (das quais 15,9 milhões no Brasil). Na classificação de países de acordo com a privação de alimentos, o Brasil está na categoria moderada (percentagem de subnutridos entre 5\% e 19\%), com um contingente de afetados da ordem de 10\% da população no período 1996 - 1998.

Na realidade, a tendência declinante no nível de desnutrição mundial, observada durante parte da década dos 90, interrompeu-se a partir de 1998. Sem uma ação decidida, que consista num ataque frontal ao problema e seja colocada em um contexto de preocupação estratégica, são escassas as probabilidades de que o número de seres humanos vitimados pela fome se reduza significativamente e, em conseqüência, que se afaste o perigo latente que o problema representa para a estabilidade política dos Estados afetados.

Para um país como o Brasil, há tempos não se pode mais pensar em recorrer à assistência da comunidade internacional para suprir o déficit alimentar. De uma parte, porque os volumes da ajuda alimentar mundial são declinantes, como evidenciam os compromissos assumidos a cada ano na conferência internacional sobre a matéria (Food Aid Convention), os quais caíram de 10,8 milhões de toneladas de cereais em 1998/99 para 7,5 milhões de toneladas em 1999/2000, seu nível mais baixo em vinte anos. Além disso, a assistência alimentar internacional tem sido cada vez mais orientada para atender a situações de emergência em várias áreas do mundo - sobretudo na África - aprisionadas no círculo vicioso fome/conflito/refugiados/mais fome. Enquanto em 1989 os recursos do Programa Mundial de Alimentos ainda se repartiam grosso modo entre 66\% para o desenvolvimento de atividades voltadas para a produção de alimentos e $34 \%$ para emergências, mais recentemente essa repartição tem sido de apenas 
cerca de 25\% para desenvolvimento e 75\% para emergências. Finalmente, a vocação do país para a produção agrícola - ancorada na existência dos recursos naturais e humanos necessários - e a pressão de outros setores da economia nacional sobre as reservas cambiais levam à exclusão da importação permanente de alimentos como solução para o problema. Existe assim, hoje em dia, uma consciência clara de que o problema da segurança alimentar no Brasil tem que ser resolvido internamente, pelos brasileiros.

A natureza da questão é conhecida, principalmente através das análises do IPEA e de órgãos internacionais, as quais revelam sérias deficiências tanto do lado da oferta quanto da demanda de alimentos no país. De um lado, sobressaem a baixa produtividade por uso de técnicas e insumos pouco adequados, a falta de irrigação, as perdas ocasionadas por pragas e roedores, as grandes deficiências em matéria de embalagem, armazenamento e transporte, a ineficiência e alto custo dos sistemas de comercialização, a escassez de financiamento e, como sério agravante, a estrutura perversa de distribuição de terras. Do outro lado, avulta o problema fundamental do baixíssimo poder aquisitivo daqueles 15,9 milhões de brasileiros, insuficiente para atender ao custo de aquisição da quantidade mínima de alimentos necessária a sua nutrição. Resulta óbvia a necessidade de ações destinadas a reduzir as inúmeras deficiências do lado da oferta e, ao mesmo tempo, a reforçar a demanda através da geração de emprego - e renda - para aquela massa de cidadãos, de forma a alcançar o que o IPEA descreve como "convergência entre o poder aquisitivo da grande maioria dos trabalhadores brasileiros e os preços de uma alimentação adequada”.

Nesse particular é que se torna importante também a ação da comunidade internacional, como mais uma forma de sensibilizar a sociedade civil em cada país para a imperiosa necessidade de engajar-se definitivamente nesse empreendimento. A FAO, que está prestes a celebrar 55 anos de existência, vem buscando maior ressonância para sua prioridade número um, na verdade sua razão de ser, que é o combate à fome e à desnutrição no mundo. Depois de ter realizado em 1974 a Conferência Mundial da Alimentação, em 1992 a Conferência Internacional sobre Nutrição e, em 1996, a Cúpula Mundial de Alimentação, aquela agência especializada das Nações Unidas volta a conclamar os países membros a realizarem uma preparação cuidadosa para a conferência de novembro deste ano, quando se avaliará o progresso realizado nos cinco anos decorridos desde a Cúpula de 1996, em matéria de implementação do Plano de Ação adotado na ocasião.

O Plano de Ação parte da constatação de que, para melhorar o acesso aos alimentos, é imprescindível erradicar a pobreza. Ao definir sete compromissos assumidos pelos governos dos países membros, o Plano explicita a base para ação em cada um deles e indica objetivos específicos (num total de 27) a serem atingidos. As medidas de apoio vão desde o desenvolvimento da infra-estrutura, da saúde, da educação e da extensão rural, até a atração de investimentos no campo, assistência 
a assentamentos, estímulo à pequena empresa e conservação do meio ambiente. O objetivo global é reduzir fortemente a subnutrição, no mais curto prazo possível. Na cúpula de 1996 foi impossível alcançar um consenso em torno de uma meta para a completa erradicação da fome, tendo-se estabelecido como objetivo reduzir o número de desnutridos à metade até o ano de 2015 e, após algum tempo, alcançar segurança alimentar para todos.

Lamentavelmente, conforme o último relatório do Comitê de Segurança Alimentar Mundial da FAO (Setembro de 2000), os dados integrados mais recentes - até 1998 - indicam a manutenção de um nível total de 826 milhões de subnutridos no mundo, sendo 792 milhões nos países em desenvolvimento e 34 milhões nos países desenvolvidos. Este é o mesmo nível dos dois anos precedentes. Segundo esse relatório, as projeções atualmente apontam para uma redução no número total de subnutridos, até 2015, muito inferior à meta estabelecida pela Cúpula (ainda haverá, então, 580 milhões de pessoas com fome, em vez de 400 milhões).

Para melhor atacar o problema, caberia promover, dentro da diversidade de características dos países afetados pela fome, certa unidade de visão e alguns critérios básicos que orientem a busca das melhores soluções. É importante, por exemplo, que se enunciem com maior precisão alguns conceitos básicos, como a própria definição de segurança alimentar. É desejável que segurança alimentar seja definida de forma simples e abrangente. Simples para que seja facilmente compreendida por todos e abrangente para poder ser ajustada, em sua aplicação, às necessidades de cada segmento da população-alvo, sem excluir qualquer deles. Tampouco deve o conceito ser explicitado em termos de uma percentagem razoável ou realista dessa população. Independentemente do número de calorias e das gramas de proteína e micro-nutrientes em que se baseia, o que varia segundo países e regiões, segurança alimentar deve ser definida em termos da disponibilidade permanente de alimentos aos quais todos tenham acesso. Qualquer meta inferior a 100\% de segurança alimentar é simplesmente inadequada, ética e politicamente, por implicar condescendência com a desnutrição e suas graves seqüelas. Daí a FAO ter adotado o lema Alimentos para todos. O desenho de qualquer projeto com um mínimo de possibilidade de êxito, no plano nacional ou internacional, não pode realmente deixar de visar à eliminação da miséria e da fome. Com esse objetivo, a Declaração adotada ano passado na Cúpula do Milênio, das Nações Unidas, destacou a importância de um enfoque integrado e coordenado no trato da pobreza e da segurança alimentar.

Não se pode esquecer que segurança alimentar implica, além da disponibilidade de alimentos, o acesso aos mesmos. A menos que se admita a hipótese - pouco condizente com a dignidade humana e, de resto, inviável financeiramente - de o Estado suprir eternamente alimentos gratuitos a todos os desvalidos, a única forma legal de acesso aos alimentos, para quem não os produz, é a sua aquisição. É bastante claro que, mais além da assistência emergencial, e 
sem menosprezar sua importância, a obtenção de segurança alimentar passa necessariamente pela geração de emprego, de onde vem a renda que possibilita a compra de alimentos no mercado. Deve-se, entretanto, abandonar em definitivo noções falaciosas do tipo crescimento do bolo ou do trickle down dos efeitos do crescimento até as camadas mais pobres. Isto simplesmente não ocorre na vida real. A segurança alimentar só será alcançada se as ações - diretas ou de apoio forem dirigidas prioritariamente para a criação de poder aquisitivo na populaçãoalvo.

A evolução desses conceitos no plano internacional contribui em boa medida para fazer avançar a solução do problema da fome. Não substitui, entretanto, nos países onde ainda existem fome e miséria, o esforço nacional resultante de decisão consciente, concebido como um componente estratégico do projeto de vida do país, e empreendido com mobilização intensa de todos os segmentos da população.

Ao Brasil, a Conferência da FAO em novembro próximo oferece uma dupla oportunidade. Por um lado, constitui um marco apropriado para se proceder a uma avaliação completa dos avanços obtidos na luta contra a fome no país, o que permitirá, se isto for desejado, introduzir as correções e ajustes necessários para se atingir o objetivo visado. Ao mesmo tempo, é uma excelente ocasião para melhor divulgar, interna e externamente, os resultados obtidos com os vários programas em execução, tanto no setor público, como por exemplo o da merenda escolar, da Comunidade Solidária, da bolsa-escola e da bolsa-alimentação e o PLANFOR, quanto no âmbito privado, como os das ONGs e do sistema "S". A divulgação de resultados pode representar um poderoso estímulo à maior mobilização dos vários segmentos da sociedade civil e dos organismos financeiros internacionais para colaborarem com o governo nesse combate vital.

Fevereiro, 2001 